\title{
Awareness of preservice mathematics teachers about prehistoric and ancient number systems
}

\author{
Nazan Mersin ${ }^{1 *}$, Mehmet Akif Karabörk², and Soner Durmuș ${ }^{3}$ \\ ${ }^{1}$ Department of Mathematics and Science Education, Çanakkale Onsekiz Mart University, Çanakkale, Turkey \\ ${ }^{2}$ Ministry of National Education, Atatürk Middle School, Bolu, Turkey \\ ${ }^{3}$ Department of Mathematics and Science Education, Bolu Abant İzzet Baysal University, Bolu, Turkey \\ *Corresponding author: nazan09gunduz@gmail.com
}

\section{ARTICLE HISTORY}

Received : 18 September 2020

Revised : 23 September 2020

Accepted : 11 October 2020

\section{KEYWORDS}

Ancient Number Systems; History of Mathematics; Prospective Mathematics ; Teachers;

\begin{abstract}
This study seeks to analyse the awareness of the pre-service teachers on the counting methods, systems and tools used in the prehistoric method and the Ancient period and to examine the distribution of this awareness by gender. A total of 42 sophomore-level students studying at a university in the Western Black Sea region, Turkey, participated in this exploratory case study. The data were obtained through a form consisting of 6 questions, one of which is open-ended, after the 14-week course of history of mathematics. The data collection tool included questions on the counting methods used in the pre-historic period and the Ancient Egyptian, Ancient Roman, Babylonian, Ancient Greek and Mayan number systems. The data were analysed through descriptive analysis and content analysis. The findings indicated that the pre-service teachers most reported the methods of tallying, tying a knot, token, circular disc. Also, the question on the Ancient Egyptian number system was answered correctly by all pre-service teachers, the lowest performance was observed in the question on the Mayan number system. Analysis of the answers by gender revealed that the male pre-service teachers were more likely to give false answers compared to the female pre-service teachers.
\end{abstract}

This is an open access article under the CC-BY-SA license.

\section{INTRODUCTION}

Numbers, one of the dispensable components of our lives, are so fundamental to human beings that life without them seems unimaginable. Numbers, which are essentially an abstract thought that humans slowly develop, allowed for the transition from concrete representations to abstract representations gradually throughout history (Ifrah, Bellos, Harding, Wood, \& Monk, 2000). Indeed, human beings have constantly engaged in developing various counting methods since the prehistoric period. It is known that the underlying reason for such effort is the need for people to register and monitor their property (Seker $\&$ Seker, 2018). For example, a hunter makes notches onto bones, trees or stones to keep track of the animals it hunts; a shepherd matches the number of sheep to pebbles to detect any decrease and increase after birth and death in the herd; one ties knots on coloured threads and counts these knots or uses different parts of the body to represent certain numbers. These are examples of the counting methods used in the prehistoric period. However, the fact that the calculation methods sometimes fail to give consistent results and everyone does not know the measurement units used led people to seek a different counting method. For instance, after the invention of writing, the Babylonians used cuneiform script to create a base- 60 number system; the Egyptians drew on hieroglyphic pictograms to develop a base-10 number system and the Mayans designed a base-20 counting system using only three symbols to represent very large numbers. Over time, each civilization has formed its own number system, and the systems which are simple to use and effective spread across the world when civilizations interact with each other. That is, it can be argued that the number systems we use today have been shaped into their present form after a long journey. Indeed, the numbers firstly developed by the Indians spread to Arabs, then to Europe through Arabs, and are now used all over the world.

It is reasonable to say that numbers with a long history are the first step and basis of mathematics teaching. From this standpoint, NCTM (2000) standards on numbers and operations emphasized that students from kindergarten to the 12th grade need to understand numbers, different representations of numbers, the relationships among sets of numbers and number systems, to grasp the properties of operations and how they are related, to make calculations and predictions fluently. It follows that understanding of mathematics among students and their interest in mathematics are related to how good they are at numbers. This raises the key question about how we can foster students' interest in mathematics, especially in numbers. It is stated that there are some topics that every student is already excited about and what is important is to associate the targeted subject with the subjects that the student is excited about in order to increase the student's interest in the targeted subject. In other words, if the two topics are properly related, a student's excitement about the original topic of excitement will make the topic of study excited as well (Kosheleva \& Villaverde, 2018). 
Many researchers argue that the history of mathematics is interesting for many, if not all students, and it motivates students to learn (Basibuyuk \& Soylu, 2019; Carter, 2006; Ersoy, 2015; Fauvel, 1991; Ho, 2008; Horton \& Panasuk, 2011; Jankvist, 2009; Kathumba, 2017; Kayan Fadlelmula, 2015; Lim \& Chapman, 2015; Liu, 2003; Marshall, 2000; Mersin, 2019; Tol \& Yavuz, 2016; Tzanakis et al., 2002; Yildiz \& Baki, 2016; Yildiz \& Gokcek, 2013). Further, it is known that HM helps developing high-order skills such as mathematical literacy, problem solving, creativity, communication and reasoning (Carter, 2006; Kathumba, 2017; Tzanakis et al., 2002; Wilson \& Chauvot, 2000).

Mathematics teachers need to have knowledge about HM and believe that it will be useful to students so that HM, which offers rich content to support students cognitively, affectively and socially, can be related to topics of mathematics and used in the classroom (Fauvel, 1991; Fauvel \& van Maanen, 2006; Gulikers \& Blom, 2001). Teachers gained the knowledge and awareness about MT mostly in the course of general knowledge since 2010 and in the course of history of mathematics, which has been a field course since 2018. The knowledge that pre-service teachers had in the course of HM will potentially affect the activities they will do in math courses (Cooney, 1988). This study is based on the conception that the awareness and knowledge of pre-service teachers about the use of numbers in different civilizations and societies would allow them to create different perspectives by giving examples from various number systems in the course, and that this will increase the students' interest in the course. Thus, this study aims to explore the awareness that the pre-service teachers gained on the number systems used in the pre-historic period and the ancient times after the course of HM and to compare it by gender.

\section{RESEARCH METHODS}

This study, which seeks to determine the awareness that the pre-service teachers gained on the number systems used in the pre-historic period and the ancient times after the course of HM, is an exploratory case study. An exploratory case study examines cases for which there is a lack of preliminary research or research settings limited to a specific method are not created. The absence of a specific limitation offers a flexible research setting for the researcher (Streb, 2010).

\subsection{Participants}

A total of 42 sophomore-level students (34 female and 8 male) studying in the department of primary level mathematics teaching participated in this study. The pre-service teachers who took part in this study are currently students at the department of primary level mathematics teaching in a university in the Western Black Sea region, Turkey. The reason why the participants are sophomore-level students is that students attend the course of history of mathematics in this level as participants are required to have attended this course. The data collection tool was administered to the participants after the course of history of mathematics.

\subsection{Data collection tool, process and data analysis}

Following the 14-week HM course, the participants were administered a survey consisting of a total of 6 questions, one of which is open-ended and the other five are about the transformation of the ancient number systems to the present number system. The first question of this survey, which served as the data collection tool in this study, asked the pre-service teachers about the methods or tools used by humans for counting in the prehistoric period. Other questions in this survey asked about the equivalent of the expressions given based on Ancient Roman, Ancient Egyptian, Babylonian, Mayan and Greek Athenian number systems and representations, respectively, to today's number system.

Below are the research questions:

1. What could be the tools used by people as a counting method in the prehistoric period? Describe.

2. What is the equivalent of the number expressed as "DCCLXXXVII" with Roman numerals to today's number system?

3. What is the equivalent of the number expressed as $\square \square \square$ in the ancient Egyptian period to today's number system?

4. What is the equivalent of the number expressed as

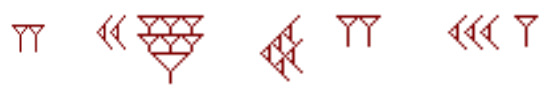
in the Babylonian

period to today's number system?

5. What is the equivalent of the number expressed as

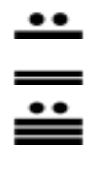

10 in the Mayan period to today's number system?

6. What is the equivalent of the number expressed as $M \Gamma^{\mathrm{N}} \Delta \Delta \triangle \Gamma \mid \mathrm{I}$ in the Greek Athenian period to today's number system?

The 14-week process (the course of history of mathematics) addressed the Ancient number systems, Egyptian-Babylonian-Ancient Greek mathematics, the Chinese Remainder theorem, Turkish-Islamic mathematics and mathematicians and the emergence of modern mathematics. The prehistoric and ancient number systems discussed in this study are the first topic of the course of history of mathematics. The translation of David M. Burton's "History of Mathematics: Introduction" was used as a source in the course of HM.

The data collection tool was designed by three researchers, one of whom was a teacher and two were academicians. The suitability of the instrument for its purpose as well as its scope were evaluated based on expert opinion, and a pilot study was conducted with students in different groups and the expressions that could cause misunderstanding were reviewed and revised. The pre-service teachers were given 40 minutes to answer the questions in the tool.

The data obtained in this study were analysed using descriptive analysis and content analysis methods. As the first question is an open-ended question on the counting tools used in the prehistoric period, content analysis was performed to 
assess this question. First, the answers given by the pre-service teachers were listed one under the other and the related concepts were identified to form the categories. Then, the resulting categories were organized into tables using frequency and percentage, and interpreted (Yildirim \& SimSek, 2013). To assess the other five questions on the equivalence of numerals used in the ancient period to today's number system, the answers of the pre-service teachers were categorized as true or false and presented using frequency and percentage.

\section{FINDINGS}

This section presents the findings from the questions in the data collection tool. The open-ended question is discussed under a separate heading whilst the other questions that asked the pre-service teachers to express the equivalence of the numerals from the ancient period to today's number system are presented together under a single heading.

\subsection{Awareness of the Pre-service Teachers on the Tools Used in the Prehistoric Period}

In the data collection form, the question of "What could be the tools used by people as a counting method in the prehistoric period?" is intended to reveal the awareness of the pre-service teachers, who attended the course of history of mathematics, on the counting methods and tools used in the ancient period. Table 1 presents the answers to this question.

Table 1. Findings on the awareness on method/tool used by humans in the pre-historic period

\begin{tabular}{lcc}
\hline Ancient period method/tool & $\mathrm{N}$ & $\%$ \\
\hline Tallying/Making notches & 42 & 100 \\
\hline Tying a knot & 31 & 73.8 \\
\hline Token/circular disc/counting pieces & 30 & 71.4 \\
\hline $\begin{array}{l}\text { Developing other numbers based on numbers } 1 \\
\text { and 2 }\end{array}$ & 12 & 28.5 \\
\hline Using body parts & 11 & \\
\hline Coloured threads & 10 & 26.1 \\
\hline Picking up stones & 3 & 7.1 \\
\hline
\end{tabular}

The answers of the pre-service teachers to the open-ended question of "What could be the tools used by people as a counting method in the prehistoric period?" were analysed and all the participants $(100 \%)$ mentioned about the method of tallying/making notches. This method was followed by tying a knot $(73.8 \%)$ and token/circular disc/counting pieces $(71.4 \%)$, which were among the most reported methods. The least mentioned method was the method collecting stones $(7.1 \%)$; besides, approximately a quarter of the pre-service teachers reported the methods of coloured threads $(23.8 \%)$, using body parts $(26.1 \%)$ and developing other numbers based on numbers 1 and $2(28.5 \%)$.

\subsection{Awareness of the Pre-Service Teachers on the Association of Numerals Used in the Ancient Civilizations with Today's Number Systems}

The survey form asked about the equivalence of the numerals used by different civilizations throughout the history to today's number systems. Table 2 presents the findings on the questions on the Ancient Roman, Ancient Egyptian, Babylonian, Mayan and Greek Athenian number systems.
Table 2. Expressing the number system/representation in the Ancient period with today's number system

\begin{tabular}{ccccc}
\hline Number systems & \multicolumn{2}{c}{ Correct } & \multicolumn{2}{c}{ Wrong } \\
\hline & $\mathrm{N}$ & $\%$ & $\mathrm{~N}$ & $\%$ \\
\hline Ancient Roman & 34 & 81 & 8 & 19 \\
\hline $\begin{array}{c}\text { Ancient } \\
\text { Egyptian }\end{array}$ & 42 & 100 & - & - \\
\hline Babylonian & 34 & 81 & 8 & 19 \\
\hline Mayan & 26 & 62 & 16 & 38 \\
\hline Greek Athenian & 33 & 78.5 & 9 & 21.5 \\
\hline
\end{tabular}

As seen in Table 2, the pre-service teachers most successfully translated the Ancient Egypt number system $(100 \%)$ to today's number system whereas they were least successful at finding the equivalent of the Mayan number system $(62 \%)$ to today's number system. The success rate at the Ancient Rome and Babylonian number systems was $81 \%$ while the rate at the Greek Athenian number system was $78.5 \%$.

The questions on the equivalent of the ancient number systems were evaluated based on the distribution of gender and false answers given individually. Table 3 shows the findings on gender.

Table 3. The distribution of the false answers by number system and gender

\begin{tabular}{lllllllll}
\hline Gender & \multicolumn{7}{c}{ Ancient number system } \\
\hline & $\begin{array}{l}\text { Ancient } \\
\text { Roman }\end{array}$ & \multicolumn{2}{l}{ Babylonian } & Mayan & \multicolumn{2}{l}{$\begin{array}{l}\text { Greek } \\
\text { Athenian }\end{array}$} \\
\hline & $\mathrm{N}$ & $\%$ & $\mathrm{~N}$ & $\%$ & $\mathrm{~N}$ & $\%$ & $\mathrm{~N}$ & $\%$ \\
\hline Female & 5 & 17.7 & 5 & 17.7 & 8 & 23.5 & 7 & 20.59 \\
\hline Male & 3 & 32.5 & 2 & 25 & 3 & 32.5 & 1 & 12.5 \\
\hline
\end{tabular}

The distribution of the false answers given to the questions on the equivalent of the ancient number systems to today's number system indicates that the male pre-service teachers gave usually more false answers based on percentage. However, the female pre-service teachers $(20.59 \%)$ gave more false answers than the male pre-service teachers $(12.5 \%)$ in the question on the Ancient Greek number system.

\section{DISCUSSION AND CONCLUSION}

This study, who examines the awareness of the pre-service teachers on the number systems and counting methods used in the prehistoric period and Ancient period, revealed that they most reported the method of tallying and making notches as the method used in the pre-historic period. The finding that all pre-service teachers mentioned the method of tallying may result from the fact that it is frequently used both in the school curriculum and our daily life. Likewise, the reason why the method of tying a knot was among the most reported methods is that it attracts the attention of the pre-service teachers and also is similar to today's number system.

As the tools of tokens and counting pieces are today used when students first learn how to count through one-to-one correspondence, the pre-service teachers may have reported these tools as they saw these tools suitable for one-to-one correspondence in the past as well. The method of picking up stones involves one-to-one correspondence; however, less pre-service teachers reported this method. As the tools of developing other numbers based on numbers 1 and 2 and using body parts to express numbers are not useful, these tools have not been used for a long time in history and attracted the attention of less pre-service teachers compared to other methods. 
Further, all participants successfully translated the Ancient Egyptian number system to today's number system; the reason may be that this number system does not use any base number and that one can reach the result only by adding the number values of the given symbols since each symbol represents a single number and the same symbol must be repeatedly used to indicate larger numbers. Also, the participants found the equivalents for the Roman and the Babylonian number systems with a high success rate as well. This is perhaps due to the fact that the pre-service teachers were familiar with the Roman number system since the primary, secondary and high school education and previously worked with this number system and that the Roman number system is still being actively used in daily life. Besides, as it requires addition-based counting, one may recall it more easily. Although the pre-service teachers did not attend any lecture on the Babylonian number system, they were as successful in this number system as they were in the Roman number system. The underlying reason may be that the Babylonian number system uses only two different symbols and represents other numbers through the repetition of these symbols, so they could easily predict what the other numbers are. Also, as we use the base-60 number system for minutes and seconds in our daily life, the pre-service teachers may be more familiar with the Babylonian number system and probably found it easier to translate the numbers.

Though more than half of the pre-service teachers gave the correct answer, the most incorrectly answered question among other number systems concerns the Mayan number system. The reason for this may be that the Mayan numbers are written vertically, from top to bottom, unlike today's number system, and that the participants failed to identify where (top or bottom) they need to start translating the numbers to today's system. Besides, operational errors are another reason why there were so many incorrect answers.

The false answers given by the pre-service teachers were also analysed by gender; the results are in favour of the female participants. The reason may be that men are lagging behind women in memorizing or more tend to take part in extracurricular activities. The analysis of the answers on an individual basis shows that some participants tended to give incomplete or incorrect answers to all questions. There is no large difference in the gender of these participants in terms of percentage. The difference is parallel to the total number of people. Thus, it should be noted that false answers are not specific to a certain number system or gender; they may rather be personal.

Overall, the research findings indicate that the awareness of the pre-service teachers on the number systems in the prehistoric period and in the Ancient period is high. The pre-service teachers attend the course of history of mathematics in the last year of their education, which may be influential on this finding. The pre-service teachers also have sufficient awareness and knowledge on this subject and this is a potentially rich source for them to foster students' interest and excitement during the teaching process (Gulikers \& Blom, 2001; Ho, 2008; Horton \& Panasuk, 2011; Liu, 2003; Tzanakis et al., 2002). In addition to this, when teachers give examples from the Mayan, Roman, Babylonian, Egyptian number systems, this helps bridging the cultural gaps in mathematics education, appreciating cultural diversity and understanding the contributions of other cultures to mathematics (Furner, 2008). That being said, further studies expand the scope of this study, which only deals with numbers, and aim to increase the awareness of mathematics teachers on different subjects.

\section{REFERENCES}

Basibuyuk, K., \& Soylu, Y. (2019). The Effect of Using History of Mathematics in Mathematics Lessons on Mathematics Attitude. Journal of Social Sciences Eskisehir Osmangazi University, 20, 1-15. doi:10.17494/ogusbd

Carter, M. D. (2006). The Role of the History of Mathematics in Middle School. (Unpublished Masters Thesis), East Tennessee State University, Tennessee, USA.

Cooney, T. J. (1988). The Issue of Reform: What Have We Learned From Yesteryear? The Mathematics Teacher, 81(5), 352-363.

Ersoy, E. (2015). Effect of using history of mathematics on the elementary school 4th grade students' academic success, retention and motivation level. (Unpublished Master Thesis), Adnan Menderes Üniversity, Aydın.

Fauvel, J. (1991). Using History in Mathematics Education. For the Learning of Mathematics, 11(2), 3-6.

Fauvel, J., \& van Maanen, J. A. (2006). History in mathematics education: The ICMI study (Vol. 6). New York, Boston, Dordrecht, London, Moscow: Kluwer Academic Publishers.

Furner, J. M. (2008). Mayan mathematics: Connecting history and culture in the classroom. Noticias de Todos, 4(2).

Gulikers, I., \& Blom, K. (2001). A historical angle', a survey of recent literature on the use and value of history in geometrical education. Educational studies in mathematics, 47(2), 223-258.

Ho, W. K. (2008). Using history of mathematics in the teaching and learning of mathematics in Singapore. Singapore Polytechnic, Singapore.

Horton, L., \& Panasuk, R. (2011). Raising awareness the history of mathematics in high school curriculum. International Journal of Humanities Social Science, 1(16), 37-46.

Ifrah, G., Bellos, D., Harding, E. F., Wood, S., \& Monk, I. (2000). The Universal History of Numbers: From Prehistory to the Invention of the Computer. Canada: Wiley.

Jankvist, U. T. (2009). A categorization of the "whys" and "hows" of using history in mathematics education. Educational studies in mathematics, 71(3), 235-261.

Kathumba, C. (2017). Investigating The Role of History of Mathematical Concepts in Learning Mathematics in Upper Secondary School Level in Malawi (Master of Education Thesis), Universty of Malawi, Chancellor College.

Kayan Fadlelmula, F. (2015). Pre-service teachers' point of views about learning history of mathematics: a case study in Turkey. BSHM Bulletin: Journal of the British Society for the History of Mathematics, 30(3), 243-252. doi:10.1080/17498430.2015.1035585

Kosheleva, O., \& Villaverde, K. (2018). How to Enhance Student Motivations by Borrowing from Ancient Tradition: Babylonian Method of Computing the Square Root. In How Interval and Fuzzy Techniques Can Improve Teaching: Processing Educational Data: From Traditional Statistical Techniques to an Appropriate Combination of Probabilistic, Interval, and Fuzzy Approaches (pp. 73-85). Berlin, Heidelberg: Springer.

Lim, S. Y., \& Chapman, E. (2015). Effects of using history as a tool to teach mathematics on students' attitudes, anxiety, motivation and achievement in grade 11 classrooms. Educational studies in mathematics, 90(2), 189-212. doi:10.1007/s10649-015-9620-4

Liu, P.-H. (2003). Do teachers need to incorporate the history of mathematics in their teaching. The Mathematics 
Teacher, 96(6), 416-421.

Marshall, G. L. (2000). Using history of mathematics to improve secondary students' attitudes toward mathematics. (Master Thesis), Illinois State University, Illinois

Mersin, N. (2019). Designing activities related to the history of mathematics for secondary school students and analysis of student reflections on these activities. (Unpublished PhD Thesis), Bolu Abant Izzet Baysal Üniversity, Bolu.

NCTM. (2000). Principles and standards for school mathematics (Vol. 1). Washington: National Council of Teachers of Mathematics.

Seker, S., \& Seker, F. (2018). Effect of Accounting in The Emergence of Abstract Counting. World of Accounting Science, 20, 790- 809.

Streb, C. K. (2010). Exploratory Case Study. In A. J. Mills, G. Durepos, \& E. Wiebe (Eds.), Encyclopedia of Case Study Research. Thousand Oaks, California: SAGE Publication. Retrieved from https://methods.sagepub.com/reference/encyc-of-c ase-study-research. doi:10.4135/9781412957397

Tol, H. Y., \& Yavuz, A. (2016). Teachers Views Related to Teaching of Mathematics Course Subjects With Their Historical Developments. European Journal of Education Studies(Special Issue), 58-73. doi:10.5281/zenodo. 204654

Tzanakis, C., Arcavi, A., de Sa, C. C., Isoda, M., Lit, C.-K., Niss, M., . . . Siu, M.-K. (2002). Integrating history of mathematics in the classroom: an analytic survey. In $\mathrm{J}$. Fauvel \& J. Van Maanen (Eds.), History in Mathematics Education: The ICMI Study (pp. 201-240). Dordrecht: Springer Netherlands.

Wilson, P. S., \& Chauvot, J. B. (2000). Sound Off!: Who? How? What? A Strategy for Using History to Teach Mathematics. The Mathematics Teacher, 93(8), 642-645.

Yildirim, A., \& SimSek, H. (2013). Qualitative Research Methods in Social Sciences. Ankara: Seckin Publication.

Yildiz, C., \& Baki, A. (2016). Teachers' views about factors which affect history of mathematics usage in lessons. Journal of Kirsehir Education Faculty, 17(2).

Yildiz, C., \& Gokcek, T. (2013). Using life stories in mathematics teaching. Paper presented at the International Symposium on Changes and New Trends in Education, Necmettin Erbakan University, Konya. 